\title{
Negative Symptoms of Schizophrenia: The Need for Conceptual Clarity
}

\begin{abstract}
When Emil Kraepelin and Eugen Bleuler consolidated the concepts of dementia praecox and schizophrenia dimost a century ago, they thought negative symptoms represented the core psychopathology of the illness. This view was not widely accepted until the past decade, which has seen a profusion of studies focusing on negative symptoms. While exciting and long overdue, the renewal of interest in these most fundamental symptoms of schizophrenia has led to a certain degree of confusion, with numerous competing concepts and definitions. Terminology itself has been confounded by the interchangeable use of very different terms such as negative, deficit, residual, defect, type II, and Kraepelinian. This lack of conceptual clarity now threatens future progress. In a recent editorial in this journal, Carpenter (1991) highlighted problems with the current "concept-free" approach to psychopathological categorization with specific reference to the negativesymptom construct. He emphasized the need to distinguish between primary and secondary negative symptoms and suggested that the deficit-nondeficit dichotomy might be the best way to conceptualize negative symptoms. We wish to identify problem areas and clarify different negative-symptom concepts and their implications. Such clarification is essential if this construct is to be of value to psychiatry.
\end{abstract}

\section{Negative Versus Positive Schizophrenia}

Negative and positive symptoms have been simplistically dichotomized by some authors in such a way as to imply that a schizophrenic patient has either positive (positive schizophrenia) or negative symptoms (negative schizophrenia). During the past decade, this dichotomous model was preeminent (Andreasen 1982, 1990). It implies that positive and negative schizophrenia are distinct illnesses or at least distinct forms (subtypes) of the same illness. Three testable prediciions of this model are: (1) "positive patients" differ from "negative patients" on various parameters, (2) such subtyping is longitudinally stable; and (3) most schizophrenic patients are classifiable as positive or negative, with mixed patients constituting a proportionally small group. These predictions have not been confirmed. While most studies have documented differences between "positive" and "negative" patients on a number of parameters, this subtyping has not been longitudinally consistent (Kay 1990); furthermore a majority of schizophrenic patients have been found to be "mixed" (e.g., Andreasen et al 1990). Finally, most investigators observe an orthogonal (and not bipolar) relationship between positive and negative syndromes, suggesting that they represent distinct dimensions (and not subtypes) of schizophrenic illness (Pogue-Geile and Keshavan 1990). 


\section{Type I Versus Type II Schizophrenia}

Crow $(1980,1985)$ used the distinction between positive and negative symptoms to postulate two types of schizophrenia: Type $I$ is characterized by positive symptoms, absence of intellectual impairment, normal brain structure, and good response to neuroleptics; and Type II is characterized by prominent negative symptoms, intellectual deterioration, enlarged cercbral ventricles, and poor response to neuroleptics. Although Type II schizophrenia was originally considered to be a later stage of illness than Type I (Crow 1980), Crow later conceptualized these two syndromes as relatively independent processes that may coexist in the same patient but follow different time courses and are different manifestations of the activity of the same pathogen (Crow 1985). In contrast to the positive/negative subtyping, the Type I/Type II classification is syndromal with postulated distinct pathophysiologies, but not distinct etiologies; furthermore, as per Crow's modified concept (1985), one does not have Type I/Type II patients, but Type I/Type II processes, which are not mutually exclusive. It should be noted that there are no operational criteria, and the distinction between Type I and Type II schizophrenia is based on a series of attributes, only one of which is the presence or absence of negative symptoms.

\section{Deficit Versus Nondeficit Schizophrenia}

Carpenter et al (1988) proposeủ a distinction between deficit and nondeficit schizophrenia based on the presence or absence of primary, enduring, negative symptoms (deficit symptoms). Deficit schizophrenic patients were believed to exhibit worse prognosis, poorer neuropsychological function, and other neurobiological abnormalities in comparison to nondeficit schizophrenic patients (Carpenter 1991). This model has enormous heuristic merit, but three definitional issues merit further attention: (1) what is the validity of the distinction between enduring and nonenduring negative symptoms? (2) what is the feasibility of making the distinction between primary and secondary negative symptoms? and (3) is deficit best conceptualized $\mathrm{s}_{s}$ a category (deficit-nondeficit) or as a dimension (severity of deficit)?

With regard to the first questior, most data support the distinction between enduring (state-independent, deficit, neurc atic-refractory) and nonenduring (state-dependent, ps 5 : chotic-phasic, neuroleptic-resporsive) negative symptoms (Kay 1990, Tandon and Greden, 1990); enduring negative symptoms generally have the characteristics described for Type II schizophrenia. While it is therefore important to delineate the entity of enduring negative symptoms, it is unclear as to when these symptoms develop in the course of schizophrenia. Some investigaiors suggest that these symptoms develop premorbidly while others suggest that they are part of postpsychotic deterioration in schizophrenia. This distinction is important in view of the controversy about the neurodevelopmental versis neurodegenerative hypotheses of schizophrenia. Conceivably, there may be both developmental and degenerative mectianisms in schizophrenia; the entity of enduring negative symptoms may be comprised of two distinct components (premorbid and postpsychotic deterioration) derived from them (Bilder et al 1985). Clinical and neurobiological correlates of these two types of enduring negative syrnptoms thus could differ, and distinguishing between them may be important. None of the current negative symptom models (including the deficit-nondeficit concept) makes this distinction.

With regard to the second question, the distinction between primaryand secondary 
negative symptoms is appealing. There is clear phenomenological overlap between negative symptoms and symptoms of depression, neuroleptic-induced extrapyramidal sideeffects (EPS), and the psychological effects of environmental deprivation, all of which occur commonly in the course of schizophrenia. As Carpenter (1991) emphasized in his editorial, clinicians/researchers are primarily interested in negative symptoms related to core (intrinsic) pathology of schizophrenia in contrast to other sources of negative symptoms. Practical difficulties arise, however, in making distinctions between primary and secondary negative symptoms. The relationship between negative and depressive symptoms is not clearly worked out. Data suggest that these constructs probably can be measured separately in schizophrenia, but the precise relationship between them is unclear. Furthermore, the concurrent presence of negative and depressive symptoms does not necessarily imply that the negative symptoms are secondary to the depressive symptoms. While there is a phenomenological overlap between akinesia and negative symptoms, negative symptoms that respond to anticholinergics or dopaminomimetic agents similarly are not necessarily secondary to EPS (Tandon and Greden 1989; Berman and Weinberger 1990). Teasing out effects of environmental deprivation is sinilarily difficult.

The third question addresses the issue of whether deficit is best conceptualized as a category (deficit-nondeficit) or as a dimension (severity). Data indicate that increasing severity of deficit symptoms is associated with more severe dysfunction and greater prevalence of various neurobiological abnormalities in schizophrenia, but is unclear whether it delineates a distinct form or subtype of the illness. While the question is unresolved, existing data are more consistent with a dimensional view (Daniel and Weinberger 1991).

\section{Other Negative Symptom Concepts}

Keefe et al $(1988,1991)$ postulate a distinction between Kraepelinian (deteriorated) versus nonKraepelinian (nondeteriorated) schizophrenia. Kraepelinian schizophrenia purportedily is associated with more severe negative symptoms, greater familial loading of schizophrenia spectrum disorders, structural brain abnormalities, and poor response to neuroleptics. The basis of classification in this scheme is outcome and severity of deterioration. "Defect" refers to a severely deteriorated state in schizophrenia. "Residual" symptoms, while embracing a broader concept, are essentially similar to enduring negative symptoms.

\section{In Conclusion}

The abundance of research reports generated by the renewed interest in the negativesymptom syndrome in schizophrenia may attest to the importance of this construct. However, one report often is difficult to compare with another. The concepts described above appear similar and overlapping, but they are not interchangeable. All have heuristic merit; on the other hand, none are proven or established. Any of the above models can be employed to conceptualize negative symptoms, but the model should be clearly stated, should be selected a priori, its implications recognized, and suitable rating instruments and statistical tests employed. For example, if one wishes to use the positive/negative model to conceptualize negative symptoms, one needs to utilize suitable instruments to dichotomize patients as positive and negative, and employ appropriate statistical tests to test any hypotheses of differences between positive and negative schizophrenic patients. Over a dozen rating instruments, each with its own conceptual bias and construct limitations, are being employed to measure and define these concepts (Silk and Tandon 1990). 
Rather than further proliferating the number of rating scales to measure this construct, there needs to be some consensus in the field about standardized methods of assessment in order to permit generalizability of findings. The issue of whether the negative syndrome reflects a dimension of pathology in all schizophrenic patients or occurs only in a subgroup of schizophrenic patients (the negative subtype) merits further inquiry. The longitudinal perspective needs to be borne in mind. When studying the association of negative symptoms with any clinical or neurobiological parameter, the phase of assessment and the rating instrument employed to measure negative symptoms are crucial sources of variance. Ideally, any relationship should be studied in different phases of the illness to evaluate its trait and state components. Finally, investigators should indicate that if one construct of negative symptoms was used in a given study, its findings do not automatically generalize to offer differing constricts.

Over the past decade we have accumulated considerable knowledge about negative symptoms. Most data support the utility of the negative-symptom construct as an organizing principle in schizophrenia. However, confusion prevails. It may even be growing, largely attributable to a multiplicity of concepts and the absence of operational definitions and standardization. To fully harness the power of this construct in unlocking the mystery of schizophrenia we need more systematic and rigorous testing of hypotheses, better use of operational definitions, improved standardization, and avoidance of generalizations from one construct to another.

Rajiv Tandon

John F. Greden

Department of Psychiatry

University of Michigan

1500 E. Medical Center Drive

Ann Arbor, MI 48109-0120

\section{References}

Andreasen NC (1982): Negative symptoms in schizophrenia: definition and reliability. Arch Gen Psychiatry 39:784-788.

Andreasen NC, Flaum M, Swayze VW, Tyrell G, Arndt S (1990): Positive and negative symptoms in schizophrenia: A critical reappraisal. Arch Gen Psychiatry 47:615-621.

Berman KF, Weinberger DR (1990): Prefrontal dopamine and defect symptoms in schizophrenia. In Greden JF, Tandon R (eds), Negative Schizophrenic Symptoms: Pathophysiology and Clinical implications. Washington DC: American Psychiatric Press, pp 81-95.

Bilder RM, Mukherjee S, Rieder RO, Pandurangi AK (1985): Symptomatic and neuropsychological components of defect states. Schizophrenia Bulletin 11:409-419.

Carpenter WT Jr. (1991): Psychopathology and common sense: Where we went wrong with negative symptoms. Biol Psychiatry 29:735-737.

Carpenter WT Jr., Heinrichs DW, Wagman AMI (1988): Deficit and nondeficit forms of schizophrenia: the concept. Am J Psychiatry 145:578-583.

Crow TJ (1980): Molecular pathology of schizophrenia: More than one disease process. $\mathrm{Br}$ Med $J$ 280:66-68.

Crow TJ (1985): The two-syndrome concept: Origins and current status. Schizophr Bull 11:471486.

Daniel DG, Weinberger DR (1991): Ex multi uno: A case for neurobiological homogeneity of 
schizophrenia. In Tamminga and Schulz (eds), Advances in Neuropsychiatry and Psychopharmacology, Volume 1, Schizophrenia Research. New York, Raven Press, pp 227-235.

Kay SR (1990): Longitudinal course of negative symptoms in schizophrenia. In Greden JF, Tandon R (eds), Negative Scnizophrenic Symptoms: Pathophysiology and Clinical Implications. Washington DC: American Psychiatric Press, pp 21-40.

Keefe RSE, Mohs RC, Davidson M, Losonczy MF, et al (1988): Kraepelinian schizophrenia: A subgroup of schizophrenia? Psychopharmacol Bull 24:56-61.

Keefe RSE, Lobel DS, Mohs RC, et al (1991): Diagnostic issues in chronic schizophrenia: Kraepelinian schizophrenia, undifferentiated schizophrenia, and state-independent negative symptoms. Schizophr Res 4:71-79.

Pogue-Geile MF, Keshavan MS (19/0): Negative symptomatology in schizophrenia: Syndrome and subtype status. In Greden JF, Tandon R (eds), Negative Schizophrenic Symptoms: Pathophysiology and Clinical Implications. Washington DC: American Psychiatric Press, pp 41-59.

Silk KR, Tandon R (1990): A comparison of negative symptom rating scales. In Greden JF, Tandon R (eds), Negative Schizophrenic Symptoms: Pathophysiology and Clinical Implications. Washington DC., American Psychiatric Press, pp 63-77.

Tandon $R$, Greden JF (1939): Cholinergic hyperactivity an negaiive schizophrenic symptoms. Arch Gen Psychiatry 46:745-753.

Tandon R, Greden JF (1990): Conclusion: Is integration possible? In Greden JF, Tandon R (eds), Negative Schizophrenic Symptoms: Pathophysiology and Clinical Implications. Washington DC: American Psychiatric Press, pp 233-239. 